\title{
A Planar Dual-Band UHF RFID Tag for Metallic Items
}

\author{
Hajar BOUAZZA ${ }^{1,2}$, Antonio LAZARO ${ }^{3}$, Mohsine BOUYA ${ }^{1}$, Abdelkader HADJOUDJA ${ }^{2}$ \\ ${ }^{1}$ TIC laboratory, International University of Rabat, Morocco \\ ${ }^{2}$ Electrical and Energetic Systems Laboratory, Ibn Tofail University Kenitra, Morocco \\ ${ }^{3}$ Dept.of Electronics, Electrics and Automatics Engineering, Universitat Rovira i Virgili (URV), Tarragona, Spain \\ hajar-bouazza@uir.ac.ma
}

Submitted January 20, 2020 / Accepted June 4, 2020

\begin{abstract}
In this paper, a comparison of three tags based on modified patches for UHF RFID in terms of size and read range performances is proposed. The antenna structure consists of a patch with an open stub and a meander line for feeding. The tags are dedicated to being mounted on metallic items and to interoperate on dual-band frequencies (European and American UHF RFID frequency bands). Moreover, the structure of the antennas is planar without any via holes or multilayers for a low cost and easy fabrication. Good agreement between simulation and experimental results has been obtained at $866 \mathrm{MHz}$ and $915 \mathrm{MHz}$.
\end{abstract}

\section{Keywords}

RFID, tags, read range, metal, impedance matching

\section{Introduction}

Radio Frequency Identification (RFID) is a very popular and widespread technology. It is used in various applications such as logistics management, asset tracking, access control, and RTLS (Real-Time Location System). One of the types of RFID technology that has grown more in recent years is the RFID technology based on passive Ultra High Frequency (UHF) tags. The UHF RFID system is composed of a tag and a reader. The tag consists of an antenna and a chip that receives power from electromagnetic waves transmitted by the reader [1]. Due to its popularity, the cost and sensitivity of the UHF RFID Integrated Circuits have been notably improved. This reduction in the sensitivity of the IC's has allowed the reading range to be increased to several meters.

However, to successfully design antennas, several factors need to be considered like their operating frequency, mounting structure, read range, and size [2], [3]. The frequency allocation for RFID systems in the UHF band and the maximum power transmitted vary in each country based on their regulations. For example, in the USA the frequency range is $902-928 \mathrm{MHz}$ with an equivalent isotropically radiated power (EIRP) of $4 \mathrm{~W}$, while in Europe it is $865-868 \mathrm{MHz}$ with an EIRP of $3.3 \mathrm{~W}$ [4]. To ensure the interoperability of the system worldwide, it is necessary to design a broad or multi-band RFID tag to cover the UHF band in the range of 860-960 MHz.

Several applications require RFID tags to be mounted on metal objects. However, the surfaces of these objects and their surrounding environment change the antenna's characteristics drastically by altering parameters like impedance matching, radiation efficiency, and the radiation pattern [5], [6].

The size of the antenna and the read range are closely related. Often, resulting in a need to compromise the read range in order to reduce the size of the tag, in an ideal case, reducing the area occupied by the antenna provides for more convenient usage, but this also results in poor performances as the read range comes down drastically. However, to overcome this, different designs are being explored for tags of similar dimensions as varying configurations have proved to have significantly different operating results.

To overcome these issues, many designs have been explored in the literature. Among these, microstrip patch antennas [7-17] have been used as they utilize a ground plane to isolate them from the effects generated by the material to which they are attached. Inverted $\mathrm{F}$ antennas and planar inverted $\mathrm{F}$ antennas (PIFA) [18-25] include a modification that achieves the tag's miniaturization by inserting via holes. However, these designs have drawbacks as the resonant frequency is very sensitive to the via hole [26] location, and there is an increase in the cost of fabrication of the antenna. Dipole-type tag antennas have also been used for designing RFID metal tags [27-29]. Still, they suffer from low radiation efficiency when placed on or near metals because of their boundary conditions [30].

In this work, we propose a planar and compact miniaturized design structure of antennas for UHF RFID tags mounted on metallic objects, operating in both the European and American frequency bands with a promising read range. Three tags are studied in Sec. 2, the first structure with the size of $139 \times 32 \times 1.6 \mathrm{~mm}^{3}$, but operating in dual bands and presenting a good read range up to $17 \mathrm{~m}$ and $15 \mathrm{~m}$ at $866 \mathrm{MHz}$ and $915 \mathrm{MHz}$, respectively. To minimize the tag size, we designed another design, which is a miniaturized structure of the first one. Still, we observed degradation in the read range performance as a result of this 
miniaturization. To improve this performance, we increased the thickness to enhance the gain, and therefore, the read range is boosted by $30 \%$. The performances of the proposed structures are validated by simulation as well as measurements in Sec. 3. Finally, the results are compared and discussed with other designs in the literature.

\section{RFID Tag Antenna Configuration}

The tag antenna designs proposed in this work are manufactured using FR-4 dielectric substrate. The antennas consist of stub loaded patches with a ground plane in the bottom. The antenna does not use via holes nor shorting strips for easy fabrication on one layer. Using thin substrates has a narrow bandwidth. Therefore, it required to know the electrical properties of the substrates to tune it at the desired operating frequency. Since the FR-4 material has a broad frequency variation in the dielectric permittivity and depends on the manufacturer, its dielectric properties have been obtained by designing a ring resonator structure on the FR-4 substrate. The transmission frequency response (parameter $S_{21}$ ) of the ring resonator is measured with a Vector Network Analyzer (VNA). The relative permittivity is calculated from the measurements of the resonant frequencies and the dimensions of the ring resonator at the UHF RFID band [31], [32]. The loss of tangent is obtained from the measurements of the resonator loaded quality factor following the procedure described in [31], [32]. The relative permittivity $\varepsilon_{\mathrm{r}}=4.69$ and loss tangent $\tan \delta=0.02$ are obtained from the measurements for the FR-4 substrate used.

The layout and dimensions of the first proposed design are presented in Fig. 1 and Tab. 1, respectively. The tag is composed of a radiation patch and an open stub for feeding and as a tuning structure [7]. The RFID chip is attached between the open stub line and the radiation patch. The antenna reactance could be tuned in a very large range with the length $L_{\mathrm{i}}$. The lengths $L_{\mathrm{r} 1}$ and $L_{\mathrm{r} 2}$ control the antenna resistance. Adjusting all these parameter dimensions could be used to obtain two resonant frequencies $866 \mathrm{MHz}$ and $915 \mathrm{MHz}$.
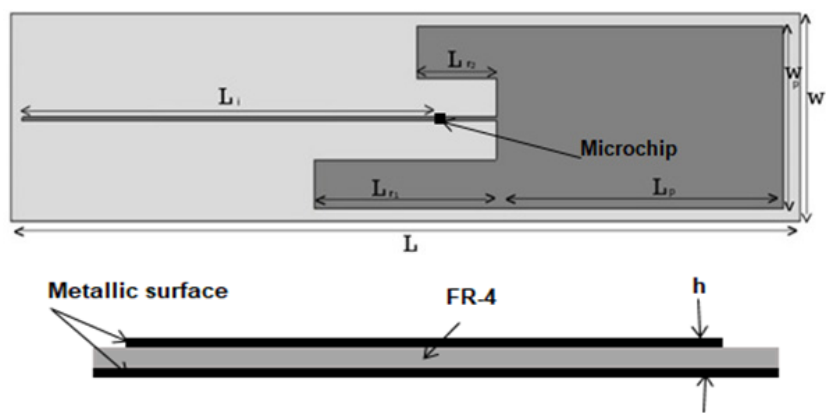

Fig. 1. The layout of the tag-based on patch loaded with a long open stub.

\begin{tabular}{|c|c|c|c|c|c|c|c|}
\hline $\boldsymbol{L}$ & $\boldsymbol{W}$ & $\boldsymbol{W}_{\mathbf{p}}$ & $\boldsymbol{L}_{\mathbf{p}}$ & $\boldsymbol{L}_{\mathbf{r} 1}$ & $\boldsymbol{L}_{\mathbf{r} 2}$ & $\boldsymbol{L}_{\mathbf{i}}$ & $\boldsymbol{h}$ \\
\hline 139 & 32 & 28 & 50.55 & 14 & 32 & 73 & 1.6 \\
\hline
\end{tabular}

Tab. 1. Dimensions in $\mathrm{mm}$ of the patch loaded with an open stub.

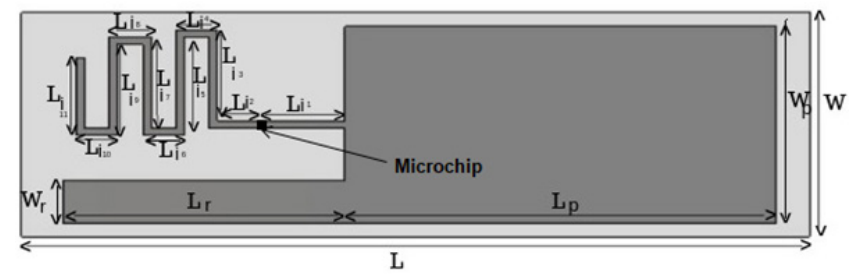

Fig. 2. The layout of the tag-based on patch loaded with the meander open stub.

\begin{tabular}{|c|c|c|}
\hline Dimensions Parameters & Second Design & Third Design \\
\hline $\boldsymbol{L}$ & 88 & 88 \\
\hline $\boldsymbol{W}$ & 32 & 32 \\
\hline $\boldsymbol{W}_{\mathbf{p}}$ & 28 & 28 \\
\hline $\boldsymbol{L}_{\mathbf{p}}$ & 51.3 & 47 \\
\hline $\boldsymbol{W}_{\mathbf{r}}$ & 6 & 3.5 \\
\hline $\boldsymbol{L}_{\mathbf{r}}$ & 34 & 38 \\
\hline $\boldsymbol{L}_{\mathbf{i} \mathbf{1}}$ & 10 & 10 \\
\hline $\boldsymbol{L}_{\mathbf{i} \mathbf{6}}=\boldsymbol{L}_{\mathbf{i} \mathbf{7}}=\boldsymbol{L}_{\mathbf{i} \mathbf{1 0}}$ & 5 & 5 \\
\hline $\boldsymbol{L}_{\mathbf{i 3}}$ & 12 & 12 \\
\hline $\boldsymbol{L}_{\mathbf{i 5}}$ & 13 & 13 \\
\hline $\boldsymbol{L}_{\mathbf{i} \mathbf{8}}=\boldsymbol{L}_{\mathbf{i} \mathbf{9}}$ & 12 & 12 \\
\hline $\boldsymbol{L}_{\mathbf{i} \mathbf{1}}$ & 10 & 12 \\
\hline $\boldsymbol{h}$ & 1.6 & 3.2 \\
\hline
\end{tabular}

Tab. 2. Dimensions in $\mathrm{mm}$ of the second and third tag-based on patch loaded with the meander stub.

The second tag is presented in Fig. 2, and its dimensions in Tab. 2, it is a miniaturized form of the first design, with a size of $88 \times 32 \times 1.6 \mathrm{~mm}^{3}$. It is a patch loaded with a meander stub. In this structure, the parameters $L_{\mathrm{in}}$ are used to adjust the antenna reactance and $L_{\mathrm{r}}$ to adjust the antenna resistance, the parameter $W_{\mathrm{r}}$ is set to adjust the $866 \mathrm{MHz}$ and $915 \mathrm{MHz}$ frequency bands.

For a gain enhancement, and to improve the read range, we designed a third tag by increasing the thickness of the substrate to $3.2 \mathrm{~mm}$ of the previous design and by adjusting the dimensions as given in Tab. 2 .

\section{Simulated and Measured Results}

\subsection{Chip Impedance Characterization}

For the optimization of the parameters, the simulations are carried out using Keysight ADS Momentum and CST Studio software.

For impedance matching and maximum power transfer, the tag antenna is designed in such a way that its impedance is the conjugate of the chip's impedance [1], [33]. The complex reflection coefficient $\Gamma$ gives the mismatch between the antenna and chip:

$$
\Gamma=\frac{Z_{\text {in }}-Z_{\text {chip }}^{*}}{Z_{\text {in }}+Z_{\text {chip }}}
$$

where $Z_{\text {in }}$ and $Z_{\text {chip }}$ are, respectively, the antenna's input impedance and the chip's input impedance. 
The chip used is an Impinj Monza R6 [34]. The IC manufacturer (Impinj Monza R6) gives a read sensitivity of up to $-20 \mathrm{dBm}$ and write sensitivity $-16.7 \mathrm{dBm}$ with a dipole antenna. These values have been taken as reference for the antenna design. The measurement of chip sensitivity is out of the scope of this work. We assume that the sensitivity is well measured by the IC manufacturer because they have access to on-wafer measurements that can be taken into account the parasitic of the test fixture better. The read range measurements presented verifie that the average sensitivity of the manufacturer is enough. The chip impedance can be modeled with an equivalent input parallel resistance $R_{\mathrm{p}}=1200 \Omega$ and equivalent input parallel capacitance $C_{\mathrm{p}}=1.43 \mathrm{pF}$. However, this equivalent circuit given by the manufacturer is for the die chip without taking into account the parasitics of the package, substrate, and input power dependence. In the prototypes, a packaged chip from Murata LXMS21ACMF-183 is used. Therefore, it is needed to characterize its impedance as a function of the frequency [35-38].

The impedances of the antenna designs and the chip are measured with an Agilent vector network analyzer (VNA) Agilent Technologies E5062A. As the input of the chip is differential, a differential probe with small parasitic should be used to ensure the closest situation to real conditions. For this purpose, a custom differential probe was made with a $\lambda / 4$ short-circuited semirigid coaxial [35] (Fig. 3a). To this end, a full two-port calibration is performed at the SMA connectors. Then, the reference planes were shifted from the measurement of the probe in an open circuit using the schematic shown in Fig. 3b. To this end, two ideal lines with negative delay were used to shift the reference plane to the chip or antenna plane. The delays were adjusted from a measurement with the probe in an open circuit. The chip or antenna is soldered at the end of the probe, and the two-port S parameters are measured with the VNA. The differential impedance of the antenna or chip is computed from the shifted two-port $\mathrm{S}$ parameters using the Keysight ADS software using the schema shown in Fig. 3c. This way is equivalent to use the conversion formulas to convert two single-ended $\mathrm{S}$ parameters to differential impedance given in [35].

The input impedances given by the manufacturer are $(13.6-\mathrm{j} 127) \Omega$ and $(12.2-\mathrm{j} 120) \Omega$ at $866 \mathrm{MHz}$ and $915 \mathrm{MHz}$, respectively. As the chip is packaged, the input impedances are slightly different. The chip impedance is a function of the input power. Therefore, to obtain the highest read range, we have chosen for the design of the antenna, the chip impedance corresponding to the chip sensitivity $(-20 \mathrm{dBm}$ from the manufacturer data). The measured impedance of the chip at different input powers (setting the VNA port power to the desired level) and the calculated chip's impedance according to the values given by the manufacturer are presented in Fig. 4. The input power level is the power level used in the VNA calibration. We have observed that the impedance remains nearly constant for power levels below $-10 \mathrm{dBm}$ because the overvoltage protection of the rectifiers is not working, and the rectifiers are working in low-power conditions. In the

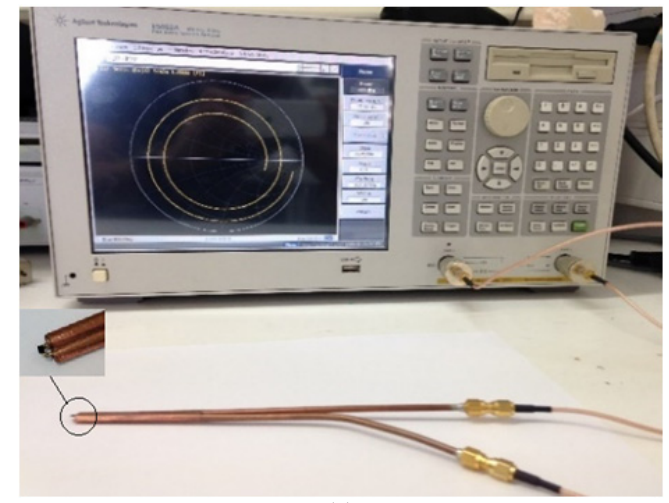

(a)

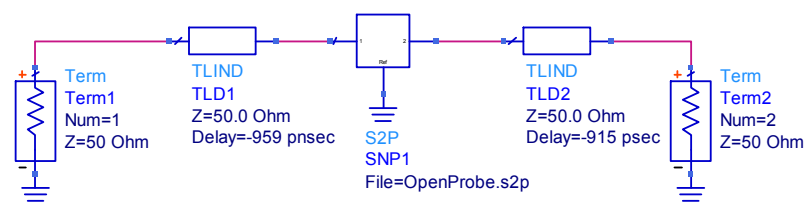

(b)

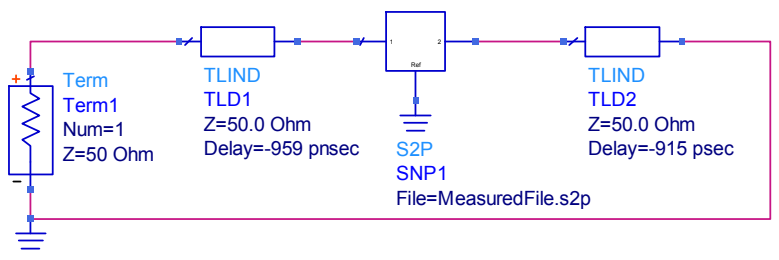

(c)

Fig. 3. Characterization setup of chip and antenna. (a) VNA and probe detail with the chip. (b) ADS circuit used to shift the reference plane from the measured $S$ parameter for an open-ended probe. (c) ADS circuit to obtain the input impedance from the measurements with the probe.

setup, a loss of about $3.4 \mathrm{~dB}$ is achieved by the mismatch of the IC (assuming that the IC is loaded with $50 \Omega$ in series when is measuring the $\mathrm{S}_{11}$ or $\mathrm{S}_{12}$ from the VNA). Therefore, the IC is receiving $-17.4 \mathrm{dBm}$ while it is measured with the probe with the VNA, but the impedance does not change a lot (see Fig. 4, where the real part is constant, and the imaginary part changes about $3 \Omega$ from $-17.4 \mathrm{dBm}$ to $-20 \mathrm{dBm}$ ). A new equivalent circuit is consisting of a shunt resistance and shunt capacitance from the real part and imaginary part of the measured chip admittance, respectively. The values found from the measurements at the input power of $-20 \mathrm{dBm}$ are $1748 \Omega$ and $1.39 \mathrm{pF}$. Good agreement has been found between the extracted shunt model (see inset circuit in Fig. 4b) and the measurements.

All the following measurements are performed, taking into account the continuous values of the chip's input impedance versus frequency.

\subsection{Simulations and Measurements of the Proposed Tag Antenna Designs}

Impedance matching between the antenna and the chip is very important in the antenna design, the simulated and measured input impedance, as well as the reflection coefficients as a function of the frequency of the first and 


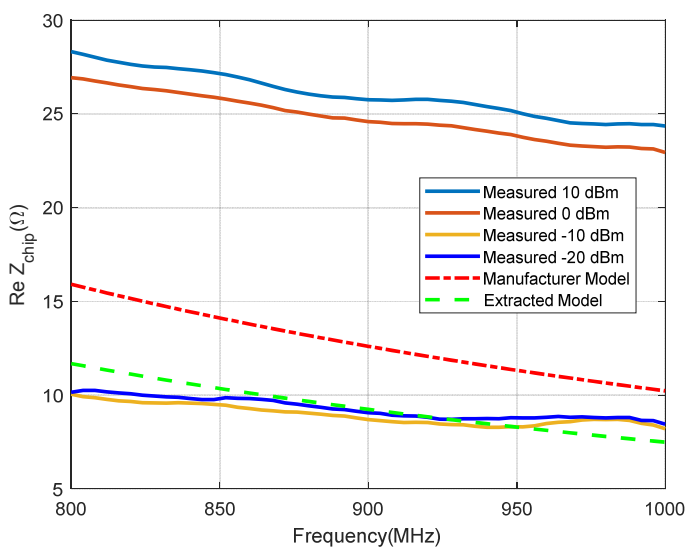

(a)

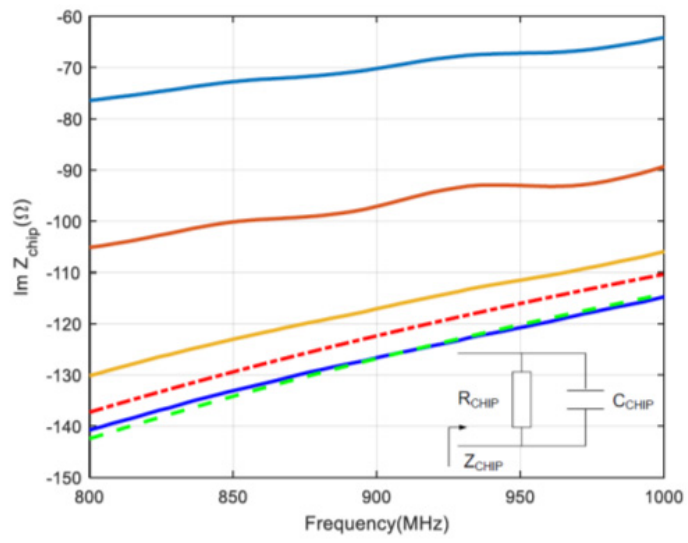

(b)

Fig. 4. Comparison of the real (top) and imaginary part (bottom) of the measured and calculated chip impedance from the manufacturer equivalent model and extracted from the measurements as a function of the frequency for different input power. The inset figure in (b) shows the equivalent shunt circuit.

second proposed antennas designs, are shown in Fig. 5, Fig. 6 and Fig. 7, respectively. The measured and simulated complex reflection coefficient is computed from the measured or simulated impedance and the measured chip impedance at $-20 \mathrm{dBm}$ using (1). It is clearly seen that the results are well matched.

Simulations of surface currents densities are illustrated in Fig. 8 to show that the proposed antennas resonate at two different resonant frequencies, $866 \mathrm{MHz}$ and $915 \mathrm{MHz}$. It is clear that the current is intensive and concentrated mainly on the open stub feed line of the first antenna design and the meander line in the second antenna design.

The read range is considered among the most important criteria of tag performance, according to the Friis transmission equation, the theoretical read range of the tag in free space can be calculated as follows [3]:

$$
R_{\max }=\frac{\lambda}{4 \pi} \sqrt{\frac{P_{\mathrm{EIRP}} G_{\mathrm{tag}}\left(1-|\Gamma|^{2}\right)}{P_{\mathrm{th}}}}
$$

where $\lambda$ is the free space wavelength of the operating frequency, $P_{\text {EIRP }}$ is the equivalent isotropic radiated power

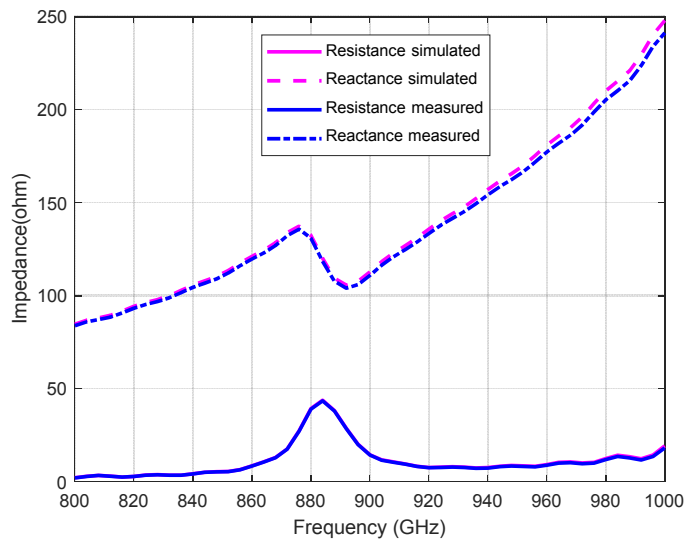

Fig. 5. Measured and simulated antenna impedance versus frequency of the first antenna design.

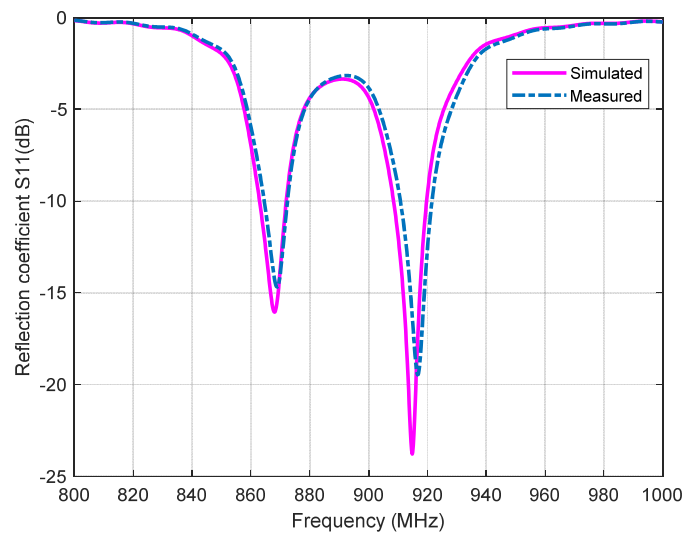

Fig. 6. Simulated and measured reflection coefficient of the proposed antenna.

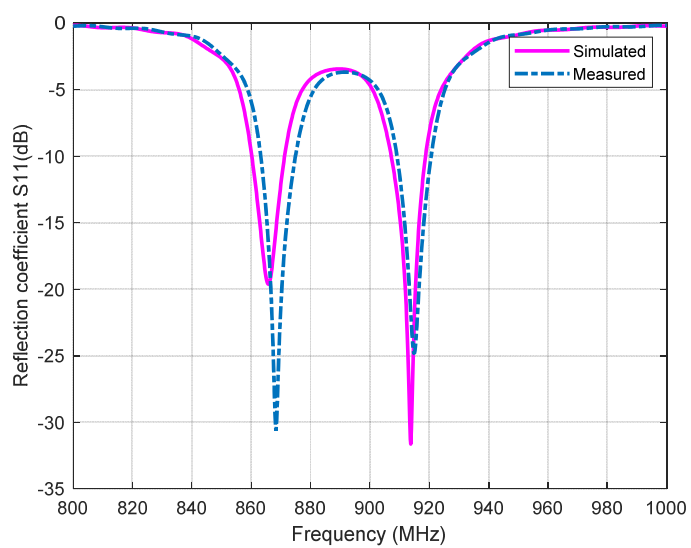

Fig. 7. Simulated and measured RL results of the second proposed antenna.

(the maximum value depend on the regulation, $3.3 \mathrm{~W}$ in EU and $4 \mathrm{~W}$ in the USA), $P_{\text {th }}$ is chip sensitivity $(-20 \mathrm{dBm})$, and $G_{\mathrm{tag}}$ is the gain of the antenna tag, its value is nearly constant over the frequency band. The product $G_{\text {tag }}\left(1-|\Gamma|^{2}\right)$ corresponds to the realized gain. The correction of the read range is achieved by the function $\left(1-||^{2}\right)$, which is the power transmission coefficient.

In order to check the simulated read range, the read ranges of the RFID tags are measured in an anechoic chamber (as shown in Fig. 9, tags mounted on the metallic 


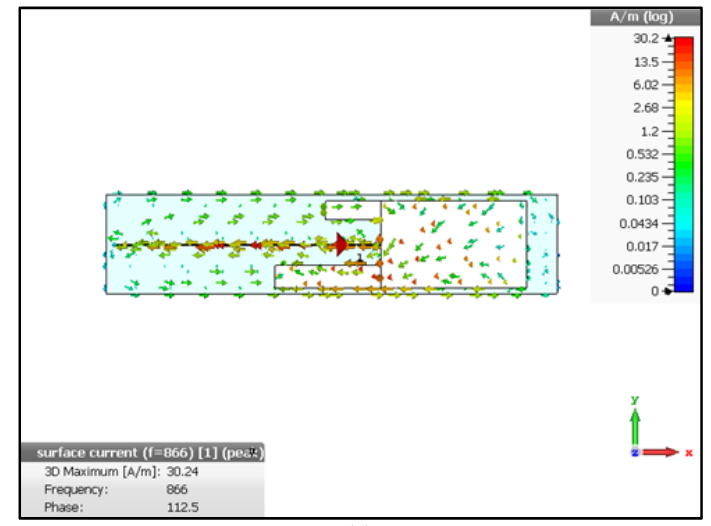

(a)

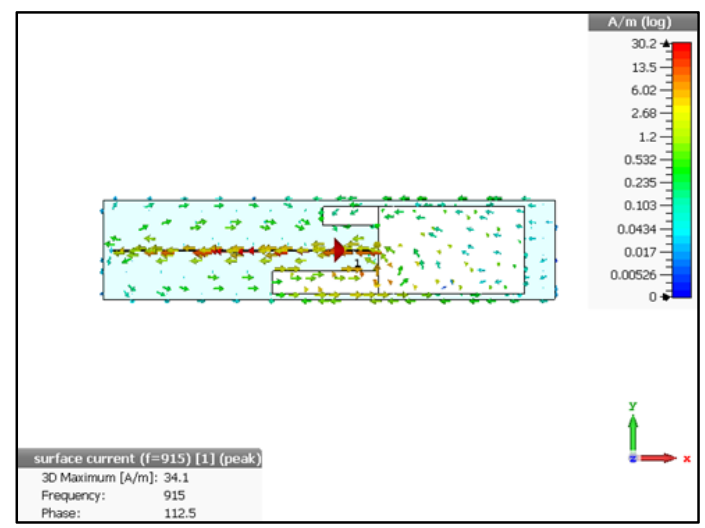

(b)

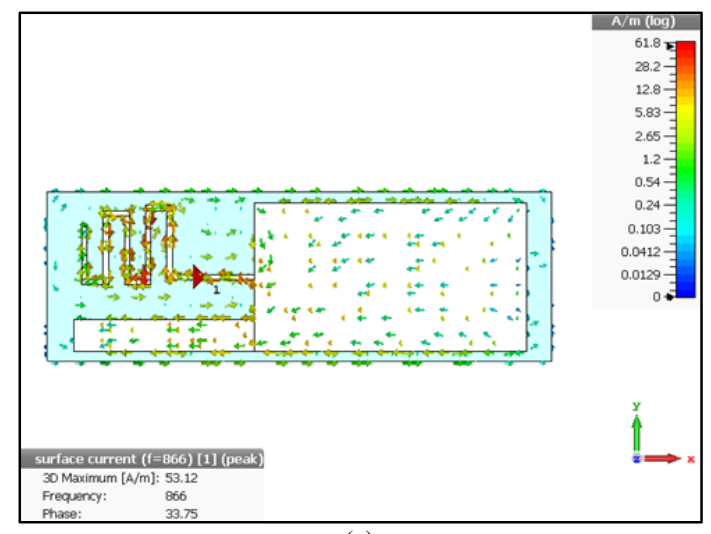

(c)

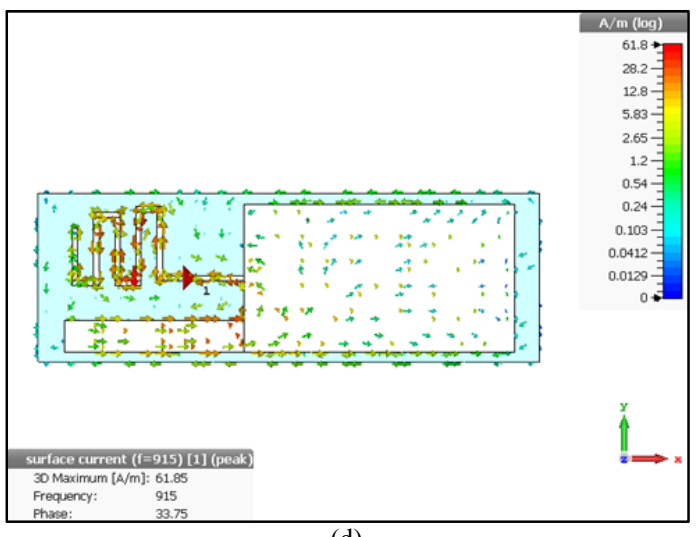

(d)

Fig. 8. Simulated currents densities of the proposed designs at $866 \mathrm{MHz}$ and $915 \mathrm{MHz}$ : (a), (b) for the first design; (c), (d) for the second design. surface), using a commercial RFID reader (Ion R4301P CAEN RFID), connected to a circularly polarized antenna with gain $\left(G_{\text {reader }}\right)$ of $8 \mathrm{~dB}$, the distance $d$ between the reader and the tag is $1.6 \mathrm{~m}$.

The measured read range, $R_{\max }$, is obtained by sweeping the reader's transmitted power in tiny steps to the tag up to receive a backscattered response frame (for Tx power $\left.P_{\text {Txmin }}\right)$. An external attenuator of $12 \mathrm{~dB}$ is used to reduce the reader's power and to ensure that the received power at the tag can reach its sensitivity. The losses of cable between the reader and reader antenna $(1.5 \mathrm{~dB})$ are taken into account. equation:

The read range is computed using the following

$$
R_{\max }=d \sqrt{\frac{P_{\mathrm{EIRP}} L}{G_{\text {reader }} P_{\mathrm{Txmin}}}}
$$

where $P_{\text {Txmin }}$ is the reader power when the tag stops to answer, $G_{\text {reader }}$ is the reader antenna gain, and $L$ is the cable and external attenuator losses. Unfortunately, commercial readers cannot select a frequency channel outside the regulations. In addition, the minimum power step is typically $0.5 \mathrm{~dB}$ [39]. To overcome this limitation, expensive tag evaluation systems such as available from the Voyantic system with $0.1 \mathrm{~dB}$ power resolution and fine frequency step can be used. To estimate the read range outside the $866 \mathrm{MHz}$ and $915 \mathrm{MHz}$ bands that cannot be measured by the reader, we computed the approximated read range from the measured antenna impedance with the probe:

$$
R_{\max } \approx R_{\text {max }, \text { mes }}\left(f_{\text {ref }}\right) \sqrt{\frac{1-|\Gamma|^{2}}{1-\left|\Gamma_{\text {ref }}\right|^{2}}}
$$

where $R_{\text {max,mes }}\left(f_{\text {ref }}\right)$ is the maximum read range measured with the reader at the channel with frequency $f_{\text {ref }}=866 \mathrm{MHz}$. Equation (4) assumes that the tag gain $\left(G_{\text {tag }}\right)$ and the sensitivity $\left(P_{\text {th }}\right)$ remain nearly constant [39]; that is, it a reasonable approximation for frequencies close to $f_{\text {ref. }} \Gamma$ in (4) is the measured complex reflection coefficient obtained with (1) for the measured antenna impedance and measured chip impedance. $\Gamma_{\text {ref }}$ is the complex reflection coefficient at the reference frequency $f_{\text {ref. The }}$ simulated and measured (using (4)) read ranges of the three proposed tags are illustrated in Fig. 10 at $3.3 \mathrm{~W}$ EIRP (corresponding to the most restrictive EU band). The measured read range of the first design is about $17.6 \mathrm{~m}$ at $866 \mathrm{MHz}$ and $16.6 \mathrm{~m}$ at $915 \mathrm{MHz}$, and the calculated read range by Friis equation reach $17.4 \mathrm{~m}$ and $16.8 \mathrm{~m}$ at $866 \mathrm{MHz}$ and $915 \mathrm{MHz}$ respectively with a realized gain of $0.94 \mathrm{~dB}$.

As expected, the second prototype, which is a miniaturized form of the first one, had a degradation in the read range performance as a result of this miniaturization, as it is seen in Fig. 10, which confirms the agreement between the size occupied and the read range, these two constraints usually depend on each other. The reached read range is $6.4 \mathrm{~m}$ and $6.1 \mathrm{~m}$ at $866 \mathrm{MHz}$ and $915 \mathrm{MHz}$ respectively with a realized gain of $-7.8 \mathrm{~dB}$. 


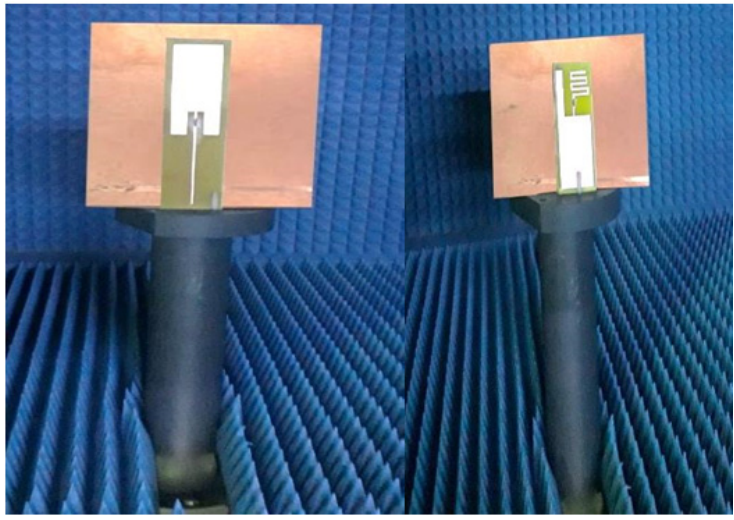

Fig. 9. Read range measurement of the proposed designs in the anechoic chamber.

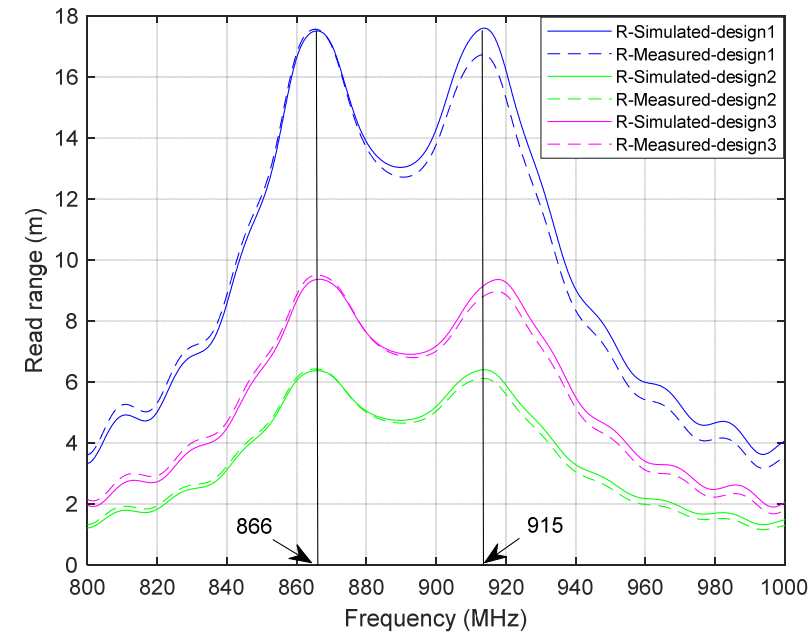

Fig. 10. Simulated and measured read ranges of the three proposed antenna designs.

\begin{tabular}{|c|c|c|c|c|c|}
\hline Ref. & $\begin{array}{c}\text { Type of the } \\
\text { tag }\end{array}$ & $\begin{array}{c}\text { Operating } \\
\text { frequency } \\
\text { bands } \\
(\mathrm{MHz}) \\
\end{array}$ & $\begin{array}{l}\text { Power } \\
\text { (EIRP) }\end{array}$ & $\begin{array}{l}\text { Tag volume } \\
\left(\mathrm{mm}^{3}\right)\end{array}$ & $\begin{array}{c}\text { Max. } \\
\text { read } \\
\text { range } \\
(\mathbf{m}) \\
\end{array}$ \\
\hline [7] & Patch & $902-928$ & $4 \mathrm{~W}$ & $108.5 \times 22 \times 3$ & 6.5 \\
\hline [8] & Patch & $\begin{array}{l}865-867 \\
902-928\end{array}$ & $\begin{array}{c}3.3 \mathrm{~W} \\
4 \mathrm{~W}\end{array}$ & $96 \times 50 \times 2$ & 4.5 \\
\hline [9] & Patch & $860-960$ & $1 \mathrm{~W}$ & $65 \times 65 \times 2$ & 3.5 \\
\hline [10] & Patch & $\begin{array}{l}865-867 \\
902-928\end{array}$ & $\begin{array}{c}3.3 \mathrm{~W} \\
4 \mathrm{~W}\end{array}$ & $106 \times 44 \times 4.6$ & 6.2 \\
\hline [11] & Patch & $903-923$ & $1 \mathrm{~W}$ & $100 \times 100 \times 1.6$ & 4.62 \\
\hline [14] & Patch & $902-928$ & $4 \mathrm{~W}$ & $50 \times 50 \times 1.8$ & 2 \\
\hline [15] & Patch & 866 & $3.3 \mathrm{~W}$ & $\begin{array}{c}100 \times 60 \times 0.76 \\
105 \times 60 \times 0.76 \\
60 \times 88 \times 0.76\end{array}$ & $\begin{array}{c}7 \\
7.3 \\
5.4\end{array}$ \\
\hline [16] & Patch & $902-928$ & $4 \mathrm{~W}$ & $32 \times 18 \times 3.2$ & 1.5 \\
\hline [17] & Patch & $902-928$ & $4 \mathrm{~W}$ & $40 \times 80 \times 1.6$ & 4.2 \\
\hline [19] & PIFA & $902-928$ & $4 \mathrm{~W}$ & $130 \times 45 \times 0.8$ & 3.1 \\
\hline [22] & $\begin{array}{c}\text { Folded } \\
\text { dipole/patch }\end{array}$ & $902-928$ & $4 \mathrm{~W}$ & $120 \times 30 \times 3.2$ & 4.3 \\
\hline$[25]$ & PIFA & $922-928$ & $4 \mathrm{~W}$ & $65 \times 20 \times 1.5$ & 3.1 \\
\hline $\begin{array}{l}\text { This } \\
\text { work }\end{array}$ & Patch & $\begin{array}{l}865-867 \\
902-928\end{array}$ & $3.3 \mathrm{~W}$ & $\begin{array}{c}139 \times 32 \times 1.6 \\
88 \times 32 \times 1.6 \\
88 \times 32 \times 3.2\end{array}$ & $\begin{array}{l}17.6 \\
6.4 \\
9.6\end{array}$ \\
\hline
\end{tabular}

Tab. 3. Comparison of UHF RFID tags mounted on metallic items.
To enhance this performance, we have to increase the thickness of the substrate to ameliorate the gain. For this reason, a third antenna tag was designed with a thickness of $3.2 \mathrm{~mm}$. The read range is improved by $30 \%$, as is shown in Fig. 10, with a realized gain of $-4.4 \mathrm{~dB}$.

Table 3 compares the proposed tags with other previous works, in terms of dimensions and read ranges, for a fair comparison, all of them are designed to be mounted on metallic items, printed on FR-4 substrate.

\section{Conclusion}

Low-cost and dual-band UHF RFID tags are studied. The performances of these designs show that they are suitable for metallic objects. The proposed structure allows an easier impedance matching of the antenna and the chip on a large scale without any further matching network. A promising read range is reached, up to $17.4 \mathrm{~m}$ in $866 \mathrm{MHz}$ and $16.8 \mathrm{~m}$ in $915 \mathrm{MHz}$, respectively, for the first proposed structure and up to $9.6 \mathrm{~m}$ and $9 \mathrm{~m}$ for the miniaturized form.

\section{Acknowledgments}

This work was supported by MESRSFC, CNRST, and Universitat Rovira i Virgili de Tarragona, partially supported by the Spanish government project RTI2018096019-B-C31.

\section{References}

[1] FINKENZELLER K. RFID Handbook. $2^{\text {nd }}$ ed., John Wiley \& Sons, 2003. ISBN: 0470844027

[2] RAO, K. V. S., NIKITIN, P. V., LAM, S. F. Antenna design for UHF RFID tags: A review and a practical application. IEEE Transactions on Antennas and Propagation, 2005, vol. 53, no. 12, p. 3870-3876. DOI: 10.1109/TAP.2005.859919

[3] MARROCCO, G. The art of UHF RFID antenna design: Impedance-matching and size-reduction techniques. IEEE Antennas and Propagation Magazine, 2008, vol. 50, no. 1, p. 66-79. DOI: 10.1109/MAP.2008.4494504

[4] Regulatory Status for Using RFID in the EPC Gen2 (860 to $960 \mathrm{MHz}$ ) Band of the UHF Spectrum. 20 pages. [Online] Cited 2020-06-04. Available at: https://www.gs1.org/docs/epc/uhf_regulations.pdf

[5] DOBKIN, D. M., WEIGAND, S. M. Environmental effects on RFID tag antennas. In IEEE MTT-S International Microwave Symposium Digest. Long Beach (CA, USA), 2005, p. 135-138. DOI: 10.1109/MWSYM.2005.1516541

[6] PENTTILÄ, K. KESKILAMMI, M., SYDÄNHEIMO, L., et al Radio frequency technology for automated manufacturing and logistics control. Part 2: RFID antenna utilization in industrial applications. The International Journal of Advanced Manufacturing Technology, 2006, vol. 31, no. 1-2, p. 116-124. DOI: $10.1007 / \mathrm{s} 00170-005-0174-y$

[7] MO, L., QIN, C. Planar UHF RFID tag antenna with open stub feed for metallic objects. IEEE Transactions on Antennas and 
Propagation, 2010, vol. 58, no. 9, p. 3037-3043. DOI: 10.1109/TAP.2010.2052570

[8] MO, L., ZHANG, H., ZHOU, H. Broadband UHF RFID tag antenna with a pair of $U$ slots mountable on metallic objects. Electronics Letters, 2008, vol. 44, no. 20, p. 1173-1174. DOI: 10.1049/el:20089813

[9] HUANG, J. Z., YANG, P. H., CHEW, W. C., et al. A compact broadband patch antenna for UHF RFID tags. In Proceedings of the 2009 Asia Pacific Microwave Conference. Singapore, 2009, p. 1044-1047. DOI: 10.1109/APMC.2009.5384364

[10] XU, L., HU, B. J., WANG, J. UHF RFID tag antenna with broadband characteristic. Electronics Letters, 2008, vol. 44, no. 2, p. 79-80. DOI: 10.1049/el: 20083009

[11] CHEN, H. D., SIM, C. Y. D., KUO, S. H. Compact broadband dual coupling-feed circularly polarized RFID microstrip tag antenna mountable on metallic surface. IEEE Transactions on Antennas and Propagation, 2012, vol. 60, no. 12, p. 5571-5577. DOI: $10.1109 /$ TAP.2012.2210273

[12] TIANG, J.-J., ISLAM, M. T., MISRAN, N., et al. Circular microstrip slot antenna for dual-frequency RFID application. Progress In Electromagnetics Research, 2011, vol. 120, p. 499-512. DOI: 10.2528/PIER11090202

[13] JAMES, J. R., HALL, P. S. (eds.) Handbook of Microstrip Antennas. London (UK): IET, 1989. DOI: 10.1049/PBEW028F

[14] KOSKINEN, T., RAJAGOPALAN, H., RAHMAT-SAMII, Y. A thin multi-slotted dual patch UHF-band metal-mountable RFID tag antenna. Microwave and Optical Technology Letters, 2011, vol. 53 , no. 1 , p. 40-47. DOI: $10.1002 /$ mop. 25622

[15] POLIVKA, M., SVANDA, M. Stepped impedance coupledpatches tag antenna for platform-tolerant UHF RFID applications. IEEE Transactions on Antennas and Propagation, 2015, vol. 63, no. 9, p. 3791-3797. DOI: 10.1109/TAP.2015.2447034

[16] CHEN, S. L. A miniature RFID tag antenna design for metallic objects application. IEEE Antennas and Wireless Propagation Letters, 2009, vol. 8, p. 1043-1045. DOI: 10.1109/LAWP.2009.2032252

[17] LEE, B., YU, B. Compact structure of UHF band RFID tag antenna mountable on metallic objects. Microwave and Optical Technology Letters, 2008, vol. 50, no. 1, p. 232-234. DOI: $10.1002 /$ mop. 23031

[18] HIRVONEN, M., PURSULA, P., JAAKKOLA, K., et al. Planar inverted-F antenna for radio frequency identification. Electronics Letters, 2004 , vol. 40, no. $14, \quad$ p. $848-850$. DOI: 10.1049/el:20045156

[19] CHEN, H. D., TSAO, Y. H. Low-profile PIFA array antennas for UHF band RFID tags mountable on metallic objects. IEEE Transactions on Antennas and Propagation, 2004, vol. 58, no. 4, p. 1087-1092. DOI: 10.1109/TAP.2010.2041158

[20] ZHANG, J., LONG, Y. A novel metal-mountable electrically small antenna for RFID tag applications with practical guidelines for the antenna design. IEEE Transactions on Antennas and Propagation, vol. 62, no. 11, p. 5820-5829. DOI: 10.1109/TAP.2014.2354412

[21] KIM, J. S., CHOI, W., CHOI, G. Y. UHF RFID tag antenna using two PIFAs embedded in metallic objects. Electronics Letters, 2008, vol. 44, no. 20 , p. 1181-1182. DOI: 10.1049/el:20080952

[22] KIM, K., SONG, J., KIM, D., et al. Fork-shaped RFID tag antenna mountable on metallic surfaces. Electronics Letters, 2007, vol. 43, no. 25 , p. 1400-1402. DOI: 10.1049/el:20072891

[23] KWON, H., LEE, B. Compact slotted planar inverted-F RFID tag mountable on metallic objects. Electronics Letters, 2005, vol. 41, no. 24, p. 1308-1310. DOI: 10.1049/el:20052940

[24] YU, B., KIM, S., JUNG, B., et al. RFID tag antenna using twoshorted microstrip patches mountable on metallic objects.
Microwave and Optical Technology Letters, 2007, vol. 49, no. 2, p. 414-416. DOI: $10.1002 /$ mop. 22159

[25] CHEN, S. L., LIN, K. H. A slim RFID tag antenna design for metallic object applications. IEEE Antennas and Wireless Propagation Letters, 2008, vol. 7, p. 729-732. DOI: 10.1109/LAWP.2008.2009473

[26] BJORNINEN, T., SYDANHEIMO, L., UKKONEN, L., et al. Advances in antenna designs for UHF RFID tags mountable on conductive items. IEEE Antennas and Propagation Magazine, 2014, vol. 56, no. 1, p. 79-103. DOI: 10.1109/MAP.2014.6821761

[27] RAUMONEN, P., SYDANHEIMO, L., UKKONEN, L., et al. Folded dipole antenna near metal plate. In IEEE Antennas and Propagation Society International Symposium Digest. Columbus (OH, USA), 2003, vol. 1, p. 848-851. DOI: 10.1109/APS.2003.1217593

[28] JEON, S., YU, Y., CHOI, J. Dual-band slot-coupled dipole antenna for $900 \mathrm{MHz}$ and $2.45 \mathrm{GHz}$ RFID tag application. Electronics Letters, 2006, vol. 42, no. 22, p. 1259-1260. DOI: 10.1049/el: 20061818

[29] FANG, Z., JIN, R., GENG, J. Asymmetric dipole antenna suitable for active RFID tags. Electronics Letters, 2008, vol. 44, no. 2, p. 44-46. DOI: 10.1049/el: 20082935

[30] MO, L. F., ZHANG, H. J., ZHOU, H. L. Analysis of dipole-like ultra-high frequency RFID tags close to metallic surfaces. Journal of Zhejiang University - Science A: Applied Physics \& Engineering, 2009, vol. 10, no. 8, p. 1217-1222. DOI: 10.1631/jzus.A0820495

[31] HEINOLA, J., TOLSA, K. Dielectric characterization of printed wiring board materials using ring resonator techniques: A comparison of calculation models. IEEE Transactions on Dielectrics and Electrical Insulation, 2006, vol. 13, no. 4, p. 717-726. DOI: 10.1109/TDEI.2006.1667729

[32] COSTA, F., PERRET, E., GENOVESI, S., et al. Progress in green chipless RFID sensors. In 11th European Conference on Antennas and Propagation (EUCAP). Paris (France). 2017, p. 3917-3921. DOI: 10.23919/EuCAP.2017.7928460

[33] LOO, C. H., Elmahgoub, K., YANG, F., et al. Chip impedance matching for UHF RFID tag antenna design. Progress In Electromagnetics Research, 2008, vol. 81, p. 359-370. DOI: 10.2528/PIER08011804

[34] NIKITIN, P. V., RAO, K. V. S., MARTINEZ, R., et al. Sensitivity and impedance measurements of UHF RFID chips. IEEE Transactions on Microwave Theory and Techniques, 2009, vol. 57, no. 1 , p. 1297-1302. DOI: 10.1109/TMTT.2009.2017297

[35] PILLAI, V. Impedance matching in RFID tags: To which impedance to match? In Proceedings of the IEEE Antennas and Propagation Society International Symposium. Albuquerque (NM, USA), 2006, p. 3505-3508. DOI: 10.1109/APS.2006.1711373

[36] KRONBERGER, R., GEISSLER, A., FriedMANN, B. New methods to determine the impedance of UHF RFID chips. In IEEE International Conference on RFID (IEEE RFID 2010). Orlando (FL, USA), p. 260-265. DOI: 10.1109/RFID.2010.5467251

[37] COLELlA, R., CHIETERA, F. P., CATARINUCCI, L. Electromagnetic performance evaluation of UHF RFID tags with power discretization error cancellation. IEEE Transactions on Antennas and Propagation, 2019, vol. 67, no. 5, p. 3545-3549. DOI: 10.1109/TAP.2019.2902708

[38] MURATA. UHF MAGISTRAP Data Sheet LXMS21ACMF-183, 2015. [Online] Cited 2020-05-29. Available at : http://www.eeworld.com.cn/zhuanti/muRata_RFID/download/LX MS21ACMF-183.pdf

[39] QING, X., GOH, C. K., CHEN, Z. N. Impedance characterization of RFID tag antennas and application in tag co-design. IEEE Transactions on Microwave Theory and Techniques, 2009, vol. 57, no. 5, p. 1268-1274. DOI: 10.1109/TMTT.2009.2017288 


\section{About the Authors ...}

Hajar BOUAZZA is a Ph.D. student at the Ibn Tofail University in collaboration with the International University of Rabat. She received her Engineering Master's degree in Electronics and Industrial Computer from the National School of Applied Science (ENSA) in Oujda in 2012. Her current research interests are antennas and RFID technologies.

Antonio LAZARO was born in Lleida, Spain, in 1971. He was awarded a Master's and a doctorate in Telecommunication Engineering by Universitat Politècnica de Catalunya (UPC) in Barcelona, Spain, in 1994 and 1998, respectively. He became a faculty member of UPC, where he currently teaches a course on microwave circuits and antennas. Since July 2004, he has been a full-time Professor in the Department of Electronic Engineering at the Universitat Rovira i Virgili (URV) in Tarragona, Spain. His research interests focus on microwave device modeling, on-wafer noise measurements, monolithic microwave integrated circuits
(MMICs), low-phase noise oscillators, MEMS, RFID, UWB, and microwave systems.

Mohsine BOUYA is currently a Director of Valorization \& Transfer Department and an Associate Professor in the Renewable Energy School of Rabat International University. He has more than 14 years of experience in research and development and innovation. He received his Ph.D. degree in Electronics Engineering from the University of Bordeaux 1, France. He was with THALES Research and Technology France, Paris, where he worked in Thales technology center in the microelectronics area (from the material to the system) for 7 years.

Abdelkader HADJOUDJA was an engineer and was awarded a doctorate in Microelectronic by the National Polytechnic Institute of Grenoble, France, in 1997. He worked for 6 years as PLD Leader Engineer Software in Atmel, Grenoble, France, and as a Consultant within Design and Reuse. Since July 2010, he became a full Professor of electronics in the Electrical and Energetic Systems Laboratory, Ibn Tofail University Kenitra. 